\title{
Pregnancy Outcomes among Adolescents in Upper Egypt
}

\section{Abdel-Naser A. Ali ${ }^{\text {a }}{ }^{\text {a }}$,Mostafa M Khodrya, Hend shrqawy M. Hassan ${ }^{\text {a }}$ Hazem H. Ahmed $^{\text {a }}$

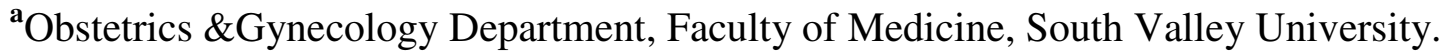

\begin{abstract}
:
Background: Teenage pregnancy is a social problem distributed worldwide, has many significant implications on mother and her baby, specifically, in developing countries. The risk of adolescent pregnancy and outcome remains a public health problem in both developed and undeveloped countries, which leads to maternal and neonatal morbidity and mortality.

Patients and methods:

This is a prospective study that included 200 teenage pregnant mothers who admitted to normal labor room for delivery or those who attended to outpatient obstetric clinic at Qena University Hospital "between April 2019 to April 2020". Information about socio- demographic data, medical history, reproductive history, current pregnancy and its complications and delivery and its outcomes are btained. Clinical examinations, Laboratory and postoperative assessment of the mother for pospartum hemorrhage was done, also assessment of newborns for Apgar score after 1 and 5 minutes was done. Then follow up of mothers till the end of perperium and assess breast feeding.

Results: The results were analyzed using Chi-square(x2) test. P (predictive) value of $<0.05$ were considered as a significant association between sociodemographic characteristics. Also there is significant relationship between extended family and complications of pregnancy.

Conclusion: The study determined that the majority of the teenage pregnant mothers were illiterate, housewives, moderate economic status, passive smokers, and without past medical diseases, neglected the antenatal care. Risk of preeclampsia and low Apgar score were higher among teenage pregnant mothers.

Recommendations: The study recommends that on pregnant teenager to have appropriate antenatal care as well as social support to avoid medical problems during pregnancy.

Key Words: Complications of Pregnancy, Outcome, Teenage Pregnancies
\end{abstract}

\section{INTRODUCTION:}

Teenage pregnancy is a social problem distributed worldwide, has many significant implications on mother and her baby, specifically, in developing countries. The risk of adolescent pregnancy and outcome remains a public health problem in both developed and undeveloped countries, which leads to maternal and neonatal morbidity and mortality (Yaseminet al., 2014). 
Conceiving in this period is known as teenage conception. Conception is a different period for women because many physical and psychological change Occur to give a new role. These changes increase and may lead to serious complications if expectant mother less than 19 years old because of teenage women's incomplete developmental task. Teenager is not well physically, psychologically and economically suitable to be pregnant with high risk for both teenage mother and child), for that reason the teenage pregnancies are considered at high risk pregnancy (Davidson, 2012)

According to (WHO, 2008), if the period between each birth decreased in teenage mother under 16 years old, the risk of mortality increased compared with other women of age 20 and over. A higher poor nutritional rate among teenage mothers than older mothers and in adequate taking of recommended daily prenatal multivitamins to maintain adequate nutritional status during gestation. Health problems likely may occur with teenage pregnancies due to smoke cigarrete, drink alcohol or take drugs during pregnancy (Health Communities Source, 2015).

Many teenage women fail to visit early prenatal care and fail to complete her education and more likely to have big families. Thus risks for pregnant Teenager women increase such as: Low birth weight, Premature birth, Pregnancy induced hypertension, Iron deficiency anemia, pregnancy induced diabetes mellitus (Davidson, 2012).

Depression among teenage mothers is higher than adult mothers because teenage experience is lower than adult mother. Considerably the teenage mothers have higher depression levels before pregnancy and after child birth than the adult mothers (Moll born et al., 2009).Literacy among teenage pregnant mother's community become high rate because young mother is unable to complete study and rearing her baby. Social legal requirement for a teenage mother has to have good work and respect from friends and family. Whole social status of teenage mother becomes destructive owing to initial pregnancy and occupy lifetime with impassive suffering and facing negative pregnancy feedback from the society (Riaand, 2016).

According to the urban child institute, it is found the women under 19 years old are deprived emotionally supportive, responsibility. Poor knowledge and awareness about child bearing and rearing than women over 19 years old (Australian Government, 2014).In developed countries versus developing countries diverse factors for teenage pregnancies comprise to society beliefs, sexual behavior, alcohol and drugs intake, teenager abuse, violence, family trouble, low self- esteem, illiteracy and low education level. In developing countries, adolescent girls have poor knowledge regarding reproductive sexual health, deficit 
of using tools to prevent pregnancies, engagement with peer pressure in sexual activity, improper use of contraception and sexual abuse which leads to poverty(Speedy remedies,2010).

\section{Aim of the work:}

The aim of the study was to determine maternal and perinatal morbidity and mortality resulting from teenage pregnancy in Upper Egypt.

\section{Patients and methods:}

A non-probability (purposive sample) of 200 teenage pregnant mothers (prime gravida, from 13-19) who admitted to normal labour room for delivery or those who follow their pregnancy in outpatient obstetrric clinic at Qena University Hospital.

\section{The Study Instrument:}

\section{1-History:}

The study instrument consisted from 6 parts as the following:-

Part 1: Socio- demographic Data: This part consists of 10 items including the age of teenage mother, Educational level, Occupation. Residence, Economic status, Type of family, no. of family, size of house .no. of rooms, smoking.

Part 2: Medical History: This part includes 9 items that asked the mother about medical disease and conditions that having or not.

Part3: Reproductive History: Part4: the state of current pregnancy.Part5: complications of current pregnancy.

\section{RESULTS:}

Part6: Delivery and Outcome.

2-Clinical examination:

A-General examination

B-Local examination

C-Abdominal and pelvic ultrasound.

3-Labaratory assessment:

4-Postoperative assessment of mother for pphge.

5-Assessment of newborns for Apgare score after 1 and 5 minutes.

5-Follow up mother till end of perperium and assess breast feeding.

-Data management and Statistical Analysis:

Analysis of data will perform by statistical package for social sciences (SPSS) version 21 as fellow:

1-Description of quantitative data as Mean and Range.

2- Description of qualitative data as number and percentage..

3-chi-square test is used to compare qualitative parameters.

4-Data will be statistically described in terms of mean, standard deviation (SD), median and range, or frequencies (number of cases)and percentages when appropriate.

5-For comparing categorical data, chisquare(x2) test will be performed. 
Table (1) shows the socio-demographic data that are related to teenage mother. The majority of study sample are (64.0> within age $>=16$ years old. Concerning the educational level, the study indicates that the majority of teenage pregnant mothers (33.0) are illiterate. Regarding to occupational status of teenage mothers, (87.0) are house wives. The socio economic status of this study sample is 54.0 moderate socioeconomic statuses. Most study subject (70.0) lived in rural area. Regarding to family type, (75.0) are extended family. In regard to smoking, (84.0) are secondary smoking. The Crowding index in this table is the index I calculated 65.0. The index 2 calculated 32.0 .the index 3 calculated 3.0.

\begin{tabular}{|c|c|c|c|}
\hline Demographic data & Rating and intervals & Frequency & Percent \\
\hline \multirow{2}{*}{ Age (Years) } & $13-16$ & 72 & 36.0 \\
\hline & $16-19$ & 128 & 64.0 \\
\hline \multirow{4}{*}{ Education level } & Illiterate & 66 & 33.0 \\
\hline & Read and write & 38 & 19.0 \\
\hline & Primary school & 46 & 23.0 \\
\hline & Secondary school & 50 & 25.0 \\
\hline \multirow{3}{*}{ Occupation } & Housewife & 174 & 87.0 \\
\hline & Student & 24 & 12.0 \\
\hline & Employment & 2 & 1.0 \\
\hline \multirow{3}{*}{ Economic status } & Sufficient & 40 & 20.0 \\
\hline & Sufficient to some extent & 108 & 54.0 \\
\hline & Insufficient & 52 & 26.0 \\
\hline \multirow{2}{*}{ Residence } & Urban & 60 & 30.0 \\
\hline & Rural & 140 & 70.0 \\
\hline \multirow{2}{*}{ Type of family } & Nuclear family & 50 & 25.0 \\
\hline & Extended family & 150 & 75.0 \\
\hline \multirow{3}{*}{ Smoking } & Nonsmoker & 28 & 14.0 \\
\hline & Smoker & 4 & 2.0 \\
\hline & passive smoker & 168 & 84.0 \\
\hline \multirow{3}{*}{ Crowing index } & $\mathrm{I}$ & 130 & 65.0 \\
\hline & 2 & 64 & 32.0 \\
\hline & 3 & 6 & 3.0 \\
\hline Total & & 200 & 100 \\
\hline
\end{tabular}

Table (2) shows that the complications of current pregnancy. In this study the majority of teenage pregnant mothers(21.0)are complicated with preeclampsia during their current pregnancy .

\begin{tabular}{|l|l|l|l|}
\hline Demographic data & Rating and intervals & Freq. & $\begin{array}{l}\text { Perc } \\
\text { ent }\end{array}$ \\
\hline \multirow{3}{*}{$\begin{array}{c}\text { Complications of } \\
\text { current pregnancy }\end{array}$} & Antepartum hemorrhage +Urinary Tract Infection & 10 & 5.0 \\
\cline { 2 - 4 } & Urinary Tract Infection+ Gestational Diabetes & 6 & 3.0 \\
\cline { 2 - 4 } & Anemia Threatened Abortion+Hyperemesisgravidarum & 32 & 16.0 \\
\cline { 2 - 4 } & Preeclampsia & 42 & 21.0 \\
\cline { 2 - 4 } & Gestational Diabetes +Preeclampsia Anemia & 6 & 3.0 \\
\cline { 2 - 4 } & Preeclampsia +Anemia +Threatened Abortion & 6 & 3.0 \\
\cline { 2 - 4 } & $\begin{array}{l}\text { Pregnancy Induced Hypertension +Threatened. Abortion } \\
\text { +Hyper emesis gravidarum }\end{array}$ & 6 & 3.0 \\
\cline { 2 - 4 } & Gestational Diabetes +Anemia +Polyhydramnios & 2 & 1.0 \\
\hline
\end{tabular}




\begin{tabular}{|c|c|c|c|}
\hline \multicolumn{4}{|c|}{\begin{tabular}{l|l}
$\begin{array}{l}\text { Anemia +Threatened. Abortion +Hyper emesisgravidarum } \\
\text { +Urinary Tract Infection }\end{array}$ & 4 \\
\end{tabular}} \\
\hline & Gestational Diabetes + Anemia. & 28 & 14.0 \\
\hline & $\begin{array}{l}\text { Anemia + Threatened Abortion +Hyper emsisgravidarum + } \\
\text { Polyhydramnios }+ \\
\text { Antepartum hemorrhage + Urinary Tract Infection }\end{array}$ & 6 & 3.0 \\
\hline & $\begin{array}{l}\text { Anemia + Pregnancy Induced Hypertension + Threatened } \\
\text { Abortion + Urinary Tract Infection } \\
\text { Antepartum hemorrhage }\end{array}$ & 2 & 1.0 \\
\hline & $\begin{array}{l}\text { Anemia + Pregnancy Induced Hypertension + Threatened } \\
\text { Abortion + Urinary Tract Infection } \\
\text { Antepartum hemorrhage }\end{array}$ & 8 & 4.0 \\
\hline & $\begin{array}{l}\text { Preeclampsia + Anemia }+ \text { Threatened Abortion }+ \\
\text { Oligohydramnios }+ \text { Antepartum hemorrhage }\end{array}$ & 4 & 2.0 \\
\hline & Gestational Diabetes + Anemia + Polyhydramnios & 2 & 1.0 \\
\hline & $\begin{array}{l}\text { Anemia }+ \text { Threatened Abortion }+ \text { Hyper emesis } \\
\text { gravidarum }+ \text { Urinary Tract Infection }\end{array}$ & 2 & 1.0 \\
\hline & $\begin{array}{l}\text { Preeclampsia + Anemia + Urinary Tract Infection }+ \\
\text { Threatened Abortion }\end{array}$ & 2 & 1.0 \\
\hline & $\begin{array}{l}\text { Gestational Diabetes + } \\
\text { Urinary Tract Infection + Antepartum hemorrhage }\end{array}$ & 4 & 2.0 \\
\hline & Oligohydramnios & 4 & 2.0 \\
\hline & $\begin{array}{l}\text { Anemia + Threatened Abortion+ Hyperemesisgravidarum } \\
+ \text { Oligohydramnios }\end{array}$ & 4 & 2.0 \\
\hline & $\begin{array}{l}\text { Anemia+ Threatened Abortion+ HEG+ Antepartum } \\
\text { hemorrhage }\end{array}$ & 2 & 1.0 \\
\hline & $\begin{array}{l}\text { Gestational Diabetes+ Polyhydramnios+ Urinary Tract } \\
\text { Infection }\end{array}$ & 4 & 2.0 \\
\hline & $\begin{array}{l}\text { Pregnancy Induced Hypertension Threatening abortion+ } \\
\text { Hyperemesisgravidarum }\end{array}$ & 4 & 2.0 \\
\hline & Threatened Abortion + Oligohydramnios & 4 & 2.0 \\
\hline & Preeclampsia + Anemia + Antepartum hemorrhage + UTI & 2 & 1.0 \\
\hline & Anemia + HEG & 4 & 2.0 \\
\hline Total & & 200 & $\begin{array}{l}100 . \\
0\end{array}$ \\
\hline
\end{tabular}

Table (3) shows the high significant relationship between socto-demograpbtc characteristics: Age Educational level, Occupation, Economic status. Residence, smoking.Crowded index with complications of pregnancy. Also there is significant relationship between extended family and complications of pregnancy. $\mathrm{P}$ value $<0.05$.

\begin{tabular}{|l|l|l|l|}
\hline & Chi-square(X2) & Df. & Value(Sig.) \\
\hline Age (Years ) & 58.471 & 25 & $0.000(\mathrm{HS})$ \\
\hline Education level & 108.953 & 75 & $0.006(\mathrm{HS})$ \\
\hline Occupation & 82.113 & 50 & $0.003(\mathrm{HS})$ \\
\hline Economic status & 105.198 & 50 & $0.00001(\mathrm{HS})$ \\
\hline Residence & 52.976 & 25 & $0.001(\mathrm{HS})$ \\
\hline
\end{tabular}




\begin{tabular}{|l|l|l|l|}
\hline type of family & 39.041 & 25 & $0.036(\mathrm{~S})$ \\
\hline Smoking & 86.735 & 50 & $0.001(\mathrm{HS})$ \\
\hline Crowded index & 119.989 & 50 & $0.000001(\mathrm{HS})$ \\
\hline
\end{tabular}

\section{DISCUSSION:}

Throughout our present study table( 1) refers to statistical distribution of the observed frequencies, percentage for some related demographic variable characteristics for the study sample. According to the mother's age/years. The majority of study samples are within age $>=16$. This result is supported with who reported that young pregnant mother under age 18 years old is $\mathrm{n}$ dominant age for complications of pregnancy and adverse outcome (Naiyereh and Morteza, 2010).

Regarding the mother's education, the present study indicates that the highest percentage of the study is uneducated. This result is in agreement with who mentioned that most adolescent mother dropout school(Gyan, 2013), and also agree with another study made by (Banerjee et al., 2009 )'who mentioned that most adolescent mothers are illiterate.

According to mother's occupation, the highest percentage is housewives. This result is supported by (Raghav and Chudhari, 2013) who reported that most adolescent pregnant mothers were housewives.

According to table (1) the result of the present study shows that the majority of study are living in rural residential area. This result supported with (Michelle,2013) who mentioned that "the teenage birth rate is greater in rural regions than major urban center".

Concerning to smoking, the present study found that most of teenage mothers are passive smokers .This result disagrees with (Vasilopoulos et al., 2015) who mentioned that cigarette smoking is the most common among teenage pregnancy.

According to table (2) the present study indicates that the majority of complications during pregnancy among teenage prime gravida mothers are Preeclampsia. This result supported with (Abdulghani et al ., 2016) who mentioned that preeclampsia is a major maternal complications among teenage pregnancy. This result agrees with another study made by (Mohamed, 2016) who stated "Teenage mothers are more susceptible to preeclampsia."

Adolescent pregnancy record high percentage of term, live birth that disagrees with (Yasemin et al., 2014) who indicated teenage pregnancy was associated with higher risk of preterm birth and still birth. Also the study results indicate the higher percentage of normal birth weight that disagree with 
(Ahlam,2011), in their study who stated that"higher incidence of low birth weight among teenage pregnancy".

Regarding to the Apgar score the present study found that most teenage pregnant mothers who gave birth with low Apgar Score agrees with(Ash and Pearl, 2014)Who mentioned most teenage pregnant mothers given birth with low Apgar score.

The table (3) show that the result of the present study reveals that a high significant relationship between Socio-demographic data and complication of pregnancy.The results are supported by (Dhora and Lika 2015) in their study who mentioned that preeclampsia (proteinuria) was detected in young pregnant mothers. The relationship between educational level and preeclampsiaare supported by (Silva et al) who mentioned that pregnant mother with low education are more likely to developed preeclampsia than educated pregnant mother.

But this result differs with (Ramesh et al.,2014)who mentioned that Low income act as numerous risk problems for pre eclampsia. Low income are related with nutritional problems, reduced prenatal care and unhygienic hygienic conditions, in addition the relationship between residency (urban) and preeclampsia in this study are supported with another study made by (Shahgheibi et al., 2016) who mentioned that preeclampsia occur in urban with high percentage than rural.(Agrawal and Walia, 2014)found that current tobacco smoking is associated with

significantly Increased risk of preeclampsia.

\section{Conclusion:}

According to the results of the present study.It confirms the following conclusions:

- Most teenage pregnant mothers were illiterate and housewives.

- Majority of teenage mothers had negative past medical diseases.

- Most of teenage mothers neglected the antenatal care.

- Risk of preeclampsia and low Apgar score are higher among teenage pregnant mothers.

- Complications of pregnancy have strong relationship between Sociodemographic data: age, educational level. occupation, residency, type of family and smoking,

\section{RECOMMENDATIONS:}

Based on the study results discussion and conclusions the study recommended that:

- Confirming on pregnant teenager to have appropriate antenatal care as well as social support to avoid medical problems during pregnancy.

- Educational programs should be emphasized to pregnant teenage mothers for increasing their knowledge and interest about pregnancy.

\section{References:}

Yasemin G, Kumar A, PariharB. 
(2014).Teenage pregnancy itsimpact on maternal and fetal outcome.International Journal of scientific study, voll.L, issue 6 . P.P.: 9.

Davidson,

London,

(2012).Ladewig:Oldsmaternalnewborn nursing and women's healthacross the lifespan, 9-edition.Printed in the United States of America. Pearson Education unit4 :Physiological risk Psychological ,sociological risk P.P.383-384.

SmithEW, Barry M, Jennifer Man love,(2013).Vaughn B.Teen Pregnancy and child bearing, Trend Child .Adolescent Health High light Publication.

Health communities Source, (2015).Prevalence of teenage pregnancy.

Moll

born

S,MorningstarE.

(2009).Investigating the relationship between teenage childbearing and psychological distress using longitudinal evidence, $50(3): 310 \cdot 26$.

Ria;Saha, (2016). 11Negative Side Effectsof Teen Pregnancy on Society by $\underline{\text { Mom }}$ Junction.org.

Urban child institute, (2014). How Adolescent Parenting Affects Children, Families, and Communities.

Ogori AF, Ajeya S,Fatima, Yunusa
AR.(2013).The cause and effect of Teenage Pregnancy: International Open Journal of Educational Research, Vol. I. NO.7. P.P:0115.P.P:12.

Speedy remedies, (2010). What are the causes of Teenage Pregnancy? http//www.speedyremedies.com/what are the cause of teenage pregnancy html.2010.

Naiyereh N, Morteza G. (2010). Maternaland Neonatal Complications in Mothers agedunder 18 years old. Journal: Patient prefer adherence, 4:219·222.

Gyan C. (2013). Effect of Teenage Pregnancy on the educational.Attainmentof girls at chador.suburbof Accra.

\section{Banerjee B,pandey GK,DuttD,SenguptaB.} (2009).Model M.: Deb S.: Teenage Pregnancy: A Socially inflected Health Hazard.

\section{Raghav,Chaudhari,Bamane}

(2013).

Teenage Pregnancy: A product ofvarioussocial and Health Factors. Indian medical, Gazette.

MichelleH. (2013).Rural teens at high risk for pregnancy analysis finds. USA TODAY.

VasilopoulosA, Gourgoulianis K, Hotzoglon C, Roupa Z. (2015).Social Influence and Smoking Habit in Adolescent.Health science journal,ISSN 1791. 809, Vol9 No. 2:5. 


\section{Australain Government,Department}

ofHealth (2014). Tobacco: Teenage and

Smoking. National Drug and Alcohol

Research Centre.https//comorbidity.edu.au/ edu.au/site/default/file/11c\%20 Tobacco-

Teenagers $\% 20$ Smoking.

\section{Abdulghani M,Tawfeq B,Salih Y.} (2016).Teenage Pregnancy Complications in Samariacity, TikritUniversity College.World Journal ofPharmacy\& Pharmaceutical sciences, ISSN 2278-4357.

MohamedA. (2016). Teenagepregnancy in Upper Egypt.Int.J. Adv.Res.Biol.Sci, 3(4): 35-41, ISSN: 2348-8069.P.P.; 35.

Yasemin GK, Ussar A,PariharB. (2014).Teenagepregnancyits impact on maternal and fetal outcome,International Journal of Scientific study, voll issue 6.p.p:9.

Ahlam A. (2011). PREGNANCY COMPLICATION AND OUTCOME AMONG TEENAGER.Thi-Qar Medical Journal (TQMI), VOL (5) NO (3): PP.(87-93).

Ash A,PearlO. (2014). Teenage pregnancy: Risk factors, outcomes and possible Targets for prevention, ISSN: 2377. 535.

DhoraandLika (Cekani) (2015), RISK FACTORS FOR PROTEINURIA IN PREGNANCY, InternationalJournal of Technical Research and Applicationse, ISSN:
2320.8163. Www. Ijtra.comspecial Issue 27.PP. 24 29.P.p.27.

Silva

LM,CoolmanSteegers

EA,JaddoeVW,MollHA,Hofimen

A,MackenbachJP,RaatH (the generation $\mathbf{R}$ study).Low socioeconomic status is a risk factor for preeclampsia.

\section{Shahgheibi S,Rezaie M,Kamangar TM,ZareaS, YousefiSR. (2016). The Effect of Season on the Prevalence of preeclampsia. J ClinGynecolObstet, 5(3): 81-84.}

Agrawal S,Walia G. (2014). Prevalence and risk factorsfor pre-eclampsia in Indian women a national cross sectional study,p.p;9. 